\title{
Design Principles of Open Innovation Concept - Universal Design Viewpoint ${ }^{*}$
}

\author{
Moyen Mohammad Mustaquim and Tobias Nyström \\ Department of Informatics and Media, Uppsala University \\ Box 513, 75120 Uppsala, Sweden \\ \{moyen.mustaquim, tobias.nystrom\}@im.uu.se
}

\begin{abstract}
The concept of open innovation is becoming an increasingly popular topic of interest and seems to promise a lot in organizational development. However, to date there are no certain design principles that can be followed by organizations on how to use open innovation successfully. In this paper seven design principles of open innovation concept have been proposed. The derived principles are the outcome which is based on the principles of universal design. The open innovation design, based on these principles could create better business values and new business strategies. Finally a theoretical framework is also proposed that shows how to use these principles for successful open innovation design.
\end{abstract}

Keywords: Open innovation, Universal Design, Design Principles for Open Innovation, Design Principles.

\section{Introduction}

The competition between corporations has sharpened in last two decades. Products and services offered by corporations need to become better and more useful for the customers. It also seems that it is more and more difficult to maintain a competitive advantage [1] among several similar corporations. Research and development done by large corporations has in the past mostly been done internally e.g. AT\&T's Bell Laboratories and IBM's Thomas J. Watson Research Center [2]. Corporations have in the past mostly relied on their own capabilities and their own resources for innovation. The innovation could be in the form of developing existing product and service or be entirely new products and services. Open innovation is a relatively new approach and concept concerning innovation. The basic idea is that a corporation should harvest outside the organizational boundaries to access new ideas that could be used in innovations (also innovations that does not fit within the organization could be divested into a new business or sold/licensed to external corporations that could benefit from it) [2].

\footnotetext{
* "The material included in this paper was orally presented at $11^{\text {th }}$ International Conference on Perspective in Business Informatics Research, September 24-26, 2012, Nizhny Novgorod, Russia, but not published."
} 
The idea of universal design is that, it offers a greater extent and possibilities of using product or service for the end users. Although the majority tends to consider universal design concept as a pattern that was strictly initiated and meant to be for people with disabilities and elderly, the attitude towards such thinking has been changing prominently in the last decade [3]. Mainstreaming universal design concept has already extended the boundaries of disability on which universal design was supposed to be considered to be based on. However universal design principles can be seen in different perspective and be altered according to the design necessity of some important design concepts like open innovation to initiate effective design [3].

Hitherto to the authors knowledge design principles for open innovation has not been explored. Considering better design principles in open innovation should increase the likelihood of successful use of the open innovation concept. In this paper we propose open innovation design principles that are derived from the universal design principles and open innovation concept's characteristics. The paper is divided into five main parts. After the introduction, in the background section we give an overview of open innovation and universal design. The next section, proposes the open innovation design principles. In section four we propose a theoretical framework that describes how to use the proposed principles. In section five a verification of the proposed principles is given followed by the last section discussion and future research.

\section{Background}

\subsection{Innovations}

Innovation has always been a force for product development and enhancement and a source for competitive advantage. The goal for all organizations is to create value and the organization uses a defined business strategy to achieve this goal [4]. The value could be created in different ways in accordance with the value chain [5]. An important way to create and capture value is to seize technological opportunities [4] through innovations (e.g. new features, new ways to use products and services etc.). Joseph Schumpeter is considered to be a pioneer in innovation theory, Schumpeter viewed innovation predominantly as innovative combination of existing things but innovation could also be in the form of new products [6]. The old paradigm on how to innovate has now been challenged by the open innovation concept.

\subsection{Open Innovation}

No definite definition of open innovation exists [7] and even the originality of open innovation is argued [8] but both open innovation as a term and as a concept was first described in articles written by Henry Chesbrough. A key part in the open innovation concept is that the business organization in the past could by itself rely on their own resources (e.g. monetary, people and material etc.) for their innovation (i.e. closed innovation) [7]. In the closed innovation model, only internal ideas for innovation is used and the corporation themselves commercialized the innovation; ideas that do not 
match the organizations business strategy is abandoned [2]. Open innovation is a paradigm shift in innovation according to Chesbrough since no single organization any longer can have all the knowledge and resources that is needed for innovation themselves [18], perhaps this could also be derived from shorter product life cycles and an increased risk of disruptive technological changes. It therefore becomes necessary for the organization to harness ideas for innovation from external stakeholders; such as customers, suppliers or even competitors. A marketplace for innovations is constructed by following the open innovation concept and this will enable better access to ideas and innovations both internal and external. Internal innovations of no value for the organization could be of value for other stakeholders and sold or licensed [9]. The collective intelligence of groups has in research revealed that more minds are often better than one; collective intelligence seems to be a good approach for idea creation [10]. Existing open innovation projects is e.g. "Connect + Develop" that Procter \& Gamble uses to improve their innovation portfolio [11]. Also the computer manufacturer Dell use open innovation in their "IdeaStorm" to use end-users as a source for new innovations and ideas [12]. "Connect + Develop" was a drastic change in Procter \& Gambles' approach to innovation and business strategy, it has now generated more than 1000 agreements with innovation partners [17]. It has also been observed that commercial organizations attach to or complement user innovation communities; examples can be found in the software development industry and sport equipment industry [13]. Open innovation is therefore becoming more important for organizations.

User involvement in the innovation process can influence and change the direction of innovation. The users enhance services and products to better serve their needs. The innovation can happen once a new set of design possibilities ("design space") is recognized by users [14]. A community consisting of users with similar needs and interest is then often formed and in the community users can share their ideas and help each other. The individual community members do not innovate in isolation or secrecy; instead they assist and help each other [15]. Active stakeholder involvement is thus crucial for successful use of open innovation without it no new ideas is generated or refined.

\subsection{Universal Design and Its Principles}

Universal design concept has been there for more than fifteen years which promises to guarantee that the surroundings, products, services and interfaces work for everybody regardless of their age and physical or mental abilities [16]. Universal design is a general approach of system design and by this approach designers ensure that their designed product or services discourses the needs of the widest possible users [3].

The original set of universal design principles was developed by a group of U.S. designers and design educators from five organizations in 1997 and is used internationally, though with variations in number and specifics analogy [16]. The seven principles summarize the properties of a design to be called universal in nature. These properties include providing equality during use, providing flexibility in use, simplicity and intuitiveness by the use of the design, easy perceptible information through the design, and high error tolerance for error, lower physical effort for the use of a particular design and optimal size and approach [3] [16]. Although based on the pillar of 
accessibility these principles has a lot more to offer than designing product of services for people with special need or disabilities. The idea of using universal design principles in this article is to integrate them with the characteristics of open innovation and thereby bring some new, better design principles; which will have positive impact on the use of open innovation. It is also important to remember and understand that universal design should not and is not a concept but a design strategy which cannot be introduced at any phase of design of a product or system. This means that, if we can integrate the strategy of universal design from the early phase of open innovation design concept, the result should be better open innovation design.

\section{Open Innovation Design Principles}

Based on the discussions of open innovation and universal design in the previous sections we understand that, since universal design is meant for reflecting better design if we can combine open innovation's characteristics with universal design principles, a structure for open innovation design principles can be established. Table 1 respectively shows the keywords of design principles properties, open innovation and universal design principles. These key words are necessary to narrate the design principles of open innovation concept which are shown in section 3.1.

Table 1. Open innovation, universal design and their corresponding characteristic matrix

\begin{tabular}{|c|c|c|}
\hline Open Innovation & Universal Design & Design Principle Properties \\
\hline $\begin{array}{l}\text { Gap Between Research and } \\
\text { Development }\end{array}$ & Equitability & $\begin{array}{l}\text { Practice of Research for the } \\
\text { Majority }\end{array}$ \\
\hline $\begin{array}{l}\text { External Stakeholder Involve- } \\
\text { ment }\end{array}$ & Flexibility & $\begin{array}{l}\text { User Participation in Broad } \\
\text { Perspective }\end{array}$ \\
\hline $\begin{array}{l}\text { Expansion of Academic Re- } \\
\text { search }\end{array}$ & Approachability & $\begin{array}{l}\text { Expanding Contact Through } \\
\text { Academia }\end{array}$ \\
\hline $\begin{array}{l}\text { Ability to Change Business } \\
\text { Model }\end{array}$ & Simplicity & $\begin{array}{l}\text { Simplicity in Business Model } \\
\text { Design }\end{array}$ \\
\hline $\begin{array}{l}\text { Introduction of Competitive } \\
\text { Strategy }\end{array}$ & Error Tolerance & $\begin{array}{l}\text { Use of Innovation in Error-Free } \\
\text { Way }\end{array}$ \\
\hline Value Chain Construction & Transparent Perception & $\begin{array}{l}\text { Understanding of Corporate } \\
\text { Strategy }\end{array}$ \\
\hline Marketplace Creation & $\begin{array}{l}\text { Reduced Psychosomatic } \\
\text { Effort }\end{array}$ & Ability to Trade Innovation \\
\hline
\end{tabular}

The properties described in column one on the Table 1, maps over with the properties in column two. The result from these two columns is shown in the column three which is in the form of aggregation of previous two column's properties. These are the foundation upon which the following derived open innovation design principles are based on. 


\subsection{Proposed Open Innovation Design Principles}

\section{Principle one: Practice of research for the majority}

Design of open innovation should focus on decreasing the gap between research and development since a gap often existed between research and the implementation of innovations into products. This could result in a superior product idea that is not possible to build in an effective way or maybe not even demanded by customers. So finding a type of equitability between research and development is anticipated.

\section{Principle Two: User Involvement in Wide-Ranging Perspective}

External stakeholders get involved in the innovation process and not only internal input is used. To create alternative paths to market and be ready to license innovation or adjust the business model especially for a major technological change, user involvement in wide ranging perspective should be considered while using open innovation concept. This could also be considered to be good risk management since more input from different stakeholders reduces the risk of negative surprises.

\section{Principle Three: Expanding Contact through Academia}

Harnessing university around the world where state of the art research is done and collaboration could be very advantageous; to do this the corporation needs to be in contact with academia. Also the corporations need to be ready to support joint collaboration with others through academia, perhaps a joint venture or business incubator. That is to maximize the leverage on investment in innovation should be considered in open innovation design.

\section{Principle Four: Simplicity in Business Model Design}

The business model should be designed in such way that it will be possible to update simply and intuitively to take advantage of open innovation. This would also make it easier to follow changes in the business strategy. Doing this will give simplicity and agility for organizational change.

\section{Principle Five: Use of Innovation for Reducing Error}

Incorporate open innovation into business strategy to gain and hold a competitive advantage towards competitors. The more stakeholders involved the less probability for undetected fault in the product or service or developing something that will not be used. That is also, to handle errors efficiently for maintaining advantages.

\section{Principle Six: Understanding of Corporate Strategy}

The design should be such that, it simplifies the understanding of where the corporation can create values and where it should outsource or buy resources. If the corporate strategy is understood by all shareholders they all can aim for the same goal. Any perceptible information in organization meant for open innovation should therefore be transparent in nature. 


\section{Principle seven: Ability to trade innovation}

The open innovation design should motivate towards creation of a marketplace where innovations can be traded. The open innovation design should also lead towards creating a portfolio of innovation to manage innovations like a stock portfolio. The creation of an effective innovation market would diminish the transaction cost. All these should be done with mental and physical efficiency.

\section{$4 \quad$ Proposed Framework}

The design principles for open innovation design proposed in the previous section results a theoretical framework that is shown in Figure 1.

The seven proposed principles are in a relation shown in Figure 1. Reduction of gap between research and development will allow flexibility in the participation of more stakeholders. This in return will allow expansion of academic research possibilities. Together research and development with more stakeholder participation and more academic enhancement will allow a business to think analytically to design their business model so that it is simple to alter. With an appropriate business model it is then possible to add any specific competitive strategies that will increase error handling ability. This can create a value chain within the corporation. Finally creation of a marketplace for trading innovation is the result of the combinatorial effect of these principles. Together these principles can result increased stakeholder involvement which is a key to successful use of the open innovation concept.

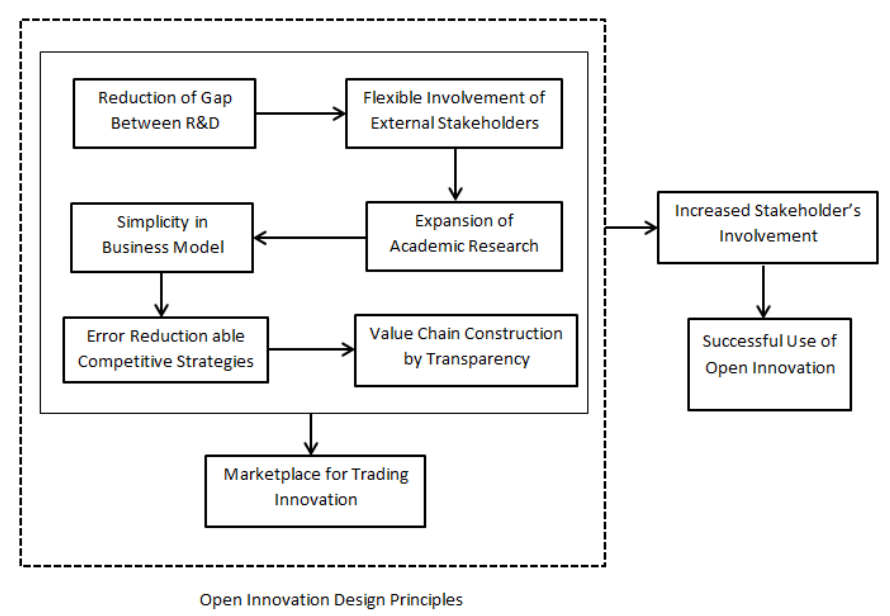

Fig. 1. A framework for open innovation design using the design principles 


\section{$5 \quad$ Verification of the Principles}

\subsection{Methods}

We wanted to study how well the proposed principles' characteristics are understood and perceived by the participants of the study. Therefore, the impacts of seven design principles towards designing system with open innovation concept have been studied by a quantitative field experiment from 31 participants. The basis for the analysis was questionnaire responses. The questionnaire items were designed to capture the variables that make up the framework. All scales used in the research were prior to the fieldwork tested and optimized for face validity with senior researchers and qualitatively tested with respondents. The test bed was set up by allowing a participant to answer a set of specific questions. They were requested to answer the questions, which were based on ranking on a scale of 1 to 7 . None of the participants had any kind of physical or mental disability that could affect understanding the survey. Basic demographic information has been collected. The age ranges of the participants were from 20 to 35. Participants were all university students. The answers from the survey were carefully analyzed by the researchers. Few participants' data were then eliminated since they did not complete the survey. The results from the questionnaires were then coded in to SPSS (version 19) and statistical operations were run to come up with results. We ran factor analysis (with factor loading value 0.40 ) together with reliability analysis to check which variable's data was not or less reliable. The rejection level was 0.7 for Chronbach's Alpha. The corrected item total value was set to be at least 0.3 for reliability analysis. The findings are described in the following section.

\section{$5.2 \quad$ Results}

Our result shows that the participants thought external stakeholders involvement, expansion to academic research and ability to change business model are something important, while they were thinking about open innovation design. Marketplace creation and introduction to competitive strategy was less prioritized as open innovation design principles by the participants. However our factor analysis returns a one factor solution (Figure 2) for explaining gap between research and development, business model changing, competitive strategy introduction, value chain creation and marketplace creation. This result is interesting because we found high statistical significance on these variables of open innovation design principles. Also Figure 3 shows one factor solution for expansion of academic research variable. Statistical significance was found here also to explain one factor which is related with other factors of the framework.

Our reliability analysis shows that data set was highly reliable with Chronbach's alpha value 0.862 (Table 2). We finally plotted the mean values of each questions and observed which questions were prioritized and less prioritized for explaining the variables of the framework. Figure 3 shows that question five and seven were ranked poorly by the participants while question two and four were highly prioritized. 


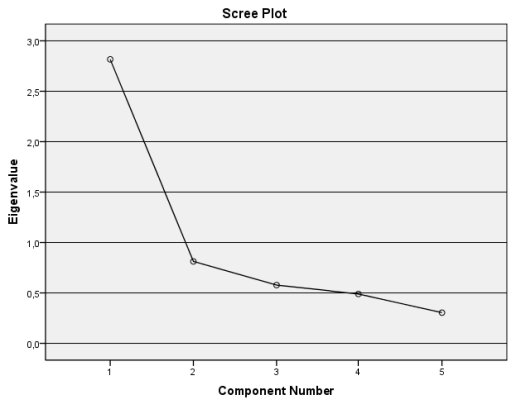

Fig. 2. One factor solution explaining five variables of the framework

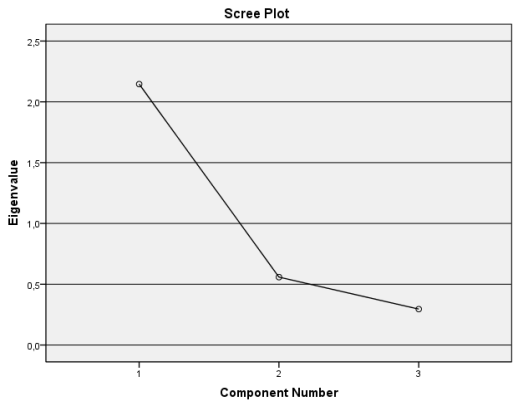

Fig. 3. One factor solution explaining academic research expansion variable

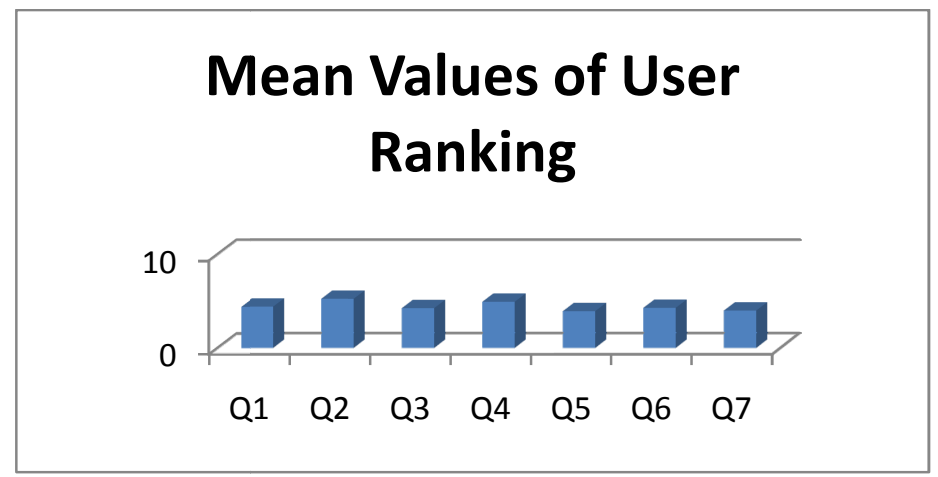

Fig. 4. Mean values of the user rankings of seven questionnaires

Table 2. Reliability analysis of the data set

Reliability Statistics

\begin{tabular}{|r|r|r|}
\hline \multicolumn{2}{|l|}{ Cronbach's Alpha } & \multicolumn{2}{|c|}{$\begin{array}{l}\text { Cronbach's Alpha Based on } \\
\text { Standardized Items }\end{array}$} \\
\hline &, 862 & N of Items \\
\hline
\end{tabular}

We came to few conclusions from these results. Ability to change business model will be optimally possible while we reduce the gap between research and development, introduce competitive strategy in business by introducing value chain construction for marketplace creation is the first interesting result. Secondly, expansion of academic research initiates by reducing gap between research and development. This in return can lead towards business model modification in a simple way with the knowledge of academia. We believe the lack of more participants and also designing of questionnaires were the primary reason for finding reduced statistical significance in understanding competitive strategy and market place creation variables. However, it was understood that the design principles that are derived by mapping universal 
design principles are not void rather valid. Also the principles follow certain steps while considering implementing them in design. The framework in Figure 2 shows the sequence at which the principles can be followed for successful implementation of open innovation strategy.

\section{Discussions and Future Research}

As of authors knowledge since there is no certain design principles available to date for using open innovation concept, the principles proposed in this paper are appealing to observe in open innovation design process. The use of open innovation is not technology dependent. Corporations find it challenging sometimes to deliver new ideas hence it should be some good reasoning towards using open innovation and factors that will motivate corporations not to use closed innovation strategies. Some of these reasoning are addressed by the proposed design principles. The proposed theoretical framework shows a combinatorial structure of successful use of open innovation using the proposed principles. The proposed framework should be interesting in the creation of new business model or altering existing business model. The idea of using universal design principles as a ground, upon which the open innovation design principles are based on, is to enhance the design principles in a more structured and better way. So far open innovation design principles proposed in this paper is one of many possible design principles, but they are surely better design principles which can be successfully applied to open innovation design concept. The idea of deriving these principles is a very new concept. Another interesting approach would be to build a larger matrix $(7 \times 7)$ with the different characteristics of open innovation and universal design to map design principle properties. The results from this paper open new possibilities of research in the field of open innovation and perhaps are imitative to design and development in HCI. The proposed framework validation and verification is an important piece initiated from this paper's result. Collecting data to verify this framework will come up with the new possibilities of understanding new design principles. Analysis of organizations using open innovation is possible in further research, which was not the scope of this paper. This in return could help improving the understanding of business strategies and how to design new business models for open innovation design.

\section{References}

1. Barney, J.: Firm resources and sustained competitive advantage. Journal of management 17(1), 99-120 (1991)

2. Chesbrough, H.: The era of open innovation. Sloan Management Review 44(3), 35-41 (2003)

3. Mustaquim, M.: Gaze Interaction - A Challenge for Inclusive Design Innovative Computing Technology. In: Pichappan, P., Ahmadi, H., Ariwa, E. (eds.) INCT 2011. CCIS, vol. 241, pp. 244-250. Springer, Heidelberg (2011) 
4. Chesbrough, H., Rosenblom, R.S.: The role of the business model in capturing value from innovation: evidence from Xerox Corporation's technology spin-off companies. Industrial and Corporate Change 11(3), 529-555 (2002)

5. Porter, M.E.: What is strategy? Harvard business review 74(4), 61-78 (1996)

6. Schumpeter, J.: Business Cycles: A theoretical, historical and statistical analysis of the Capitalist process. McGraw-Hill, New York (1939)

7. Dahlander, L., Gann, D.M.: How open is innovation? Research Policy 39(6), 699-709 (2010)

8. Trott, P., Hartmann, D.: Why 'open innovation' is old wine in new bottles. International Journal of Innovation Management 13(4), 715-736 (2009)

9. Chesbrough, H., Vanhaverbeke, W., West, J.: Open Innovation Researching a New Paradigm. Oxford University press, New York (2006)

10. Bonabeau, E.: Decisions 2.0: The Power of Collective Intelligence. MIT Sloan Management Review 50(2), 45-52 (2009)

11. Huston, L., Sakkab, N.: Connect and develop: Inside Procter \& Gamble's new model for innovation. Harvard Business Review 84(3), 58-66 (2006)

12. Di Gangi, P.M., Wasko, M.: Steal my idea! Organizational adoption of user innovations from a user innovation community: A case study of Dell Idea Storm. Decision Support Systems 48(1), 303-312 (2009)

13. Von Hippel, E.: Innovation by user communities: Learning from open-source software. MIT Sloan Management Review 42(4), 82-86 (2001)

14. Baldwin, C., Hienerth, C., et al.: How user innovations become commercial products: A theoretical investigation and case study. Research Policy 35(9), 1291-1313 (2006)

15. Franke, N., Shah, S.: How communities support innovative activities: an exploration of assistance and sharing among end-users. Research Policy 32(1), 157-178 (2003)

16. Center for Accessible Housing. Accessible environments: Toward universal design. Raleigh: North Carolina State University (1995)

17. Procter \& Gamble, "Connect + Develop", http: / /www.pg.com/connect_develop/why_partner_with_pg.shtml (accessed January 27, 2013)

18. Chesbrough, H.: Managing Open Innovation. Research Technology Management 47(1), 23-26 (2004) 